\title{
A Modeling Framework for Developing Load Profiles in Buildings
}

\author{
Patrick Ozoh \\ Department of information \\ and communication technology \\ Osun State University, Nigeria
}

\author{
Shapiee Abd-Rahman \\ Faculty of computer science \\ and information technology \\ Universiti Malaysia, Sarawak
}

\author{
Jane Labadin \\ Faculty of computer science \\ and information technology \\ Universiti Malaysia, Sarawak
}

\begin{abstract}
In this paper, the adapted time-series regression (ATSR) model is used for developing appliance energy usage profiles for a building which utilizes meter readings, and individual appliance usage using data measurements from installed power meter respectively. For this purpose, statistical models were produced for a building as well as for individual appliances. This assists in understanding the usage patterns for all types of appliances and identifies the factors that may affect the pattern. In addition, establishing a general model for a building based on different appliance use will provide more precise data than developing a model based on total consumption for the building. This will provide an insight into the contribution of each appliance on total consumption.
\end{abstract}

\section{General Terms}

Machine learning, computational science, energy informatics.

\section{Keywords}

ATSR model, usage profiles, meter readings, installed power meter, statistical models.

\section{INTRODUCTION}

A time-series regression model was used to develop load profiles for building and electricity consumption for individual appliances[1]. A study of the consumption of electric appliances in domestic buildings was carried out to identify the trends in their energy use pattern [2]. The model developed was useful for simulating energy consumption for individual appliances. The described models in these papers gave no explicit description of consumption at appliance level, and did not identify trends in energy consumption in buildings based on collected data from individual appliances. The development of a model for generating residential electricity profiles from time-use data was developed by[3]. Daily time-use data sets and energy measurements for different appliances were used to develop a model that can be used for the determination of households' energy consumption. The study demonstrated that energy use profiles can be generated from time-use data measurements with reasonable accuracy when compared with actual electricity consumption measurements. [4] described the simulation of power consumption and the development of a domestic load curve model for individual electric appliances, in order to investigate their individual power demand. The study was motivated by the need for behavioral and lifestyle modifications of household's electricity usage.
The ATSR model considers the contribution of individual appliance consumption to, in order to describe the consumption pattern for these appliances. The proposed technique is analyzed by adapting the time-series regression model [5]. The technique is applied in developing load profiles for buildings and electricity consumption for individual appliances, and is given as:

$$
y_{t+1}=\alpha+\beta t
$$

where $y_{t+1}$ is current consumption, $\alpha$ and $\beta$ are model parameters of consumption for previous years, while $t$ represents previous time period. This approach attempts to characterize the properties of the measured data in simple parametric relationships, which remain reasonably constant over time. Furthermore, the proposed technique shows the trend in consumption of the appliances by computing the standard error (SE) and coefficient of variation for electricity consumed by these appliances [6]. The modeling process examines the time series properties of the data series for ATSR model, its patterns and trends.

In utilizing ATSR model, simulation of consumption and usage patterns for a building and common appliances usage models were produced to explore the impact of various energy conservation strategies. These impacts may be at the personal level such as comfort, or at the household level such as reducing the electricity bill, or at the national level such as reducing peak power requirements. Detailed electricity consumption profiles for a building are an important prerequisite for the accurate analysis of energy saving strategies, such as controlling for appliance use. The use of air conditioning, lighting, and other electric appliances within a building varies considerably with respect to time, mainly in accordance with the activity of people in the building. It depends not only on the number of people who are in a building but also on whether they are active (i.e. using an electric appliance). [7] is a similar study to this research work. Section 2 outlines the process and methods used for this research; Section 3 and Section 4 develop load profiles for a building and individual appliances respectively, and Section 5 summarizes and concludes the paper.

\section{METHODOLOGY}

All This research investigates the energy consumption patterns of air-conditioners, lighting, computers and closedcircuit television by measuring and logging the average daily power consumption of individual appliances. Measurements were taken from the installed power meter used for the purpose of this research, which will be described later. The 
period of measurement was based on the typical period of usage for each appliance, and individual appliances were measured from January to December, 2013. Total consumption measurements in the building were also analyzed and were taken directly from the power grid for the years 2009 to 2012 as provided by the Asset Management Division, UNIMAS. In this research, each appliance is measured individually to obtain a load profile for each appliance. This will provide a good understanding of an appliance's characteristics through its usage pattern. In addition, there will be a model of each appliance used, which will include information such as the times of usage per day and their energy consumption.

Identifying a reliable solution to electricity problems should help in achieving energy efficiency. Efficient use of appliances is becoming an important issue in reducing electricity costs and wastages, as the requirement for efficient use of electricity is the minimization of electricity costs for appliance use in buildings. This is possible by accurate data collection, monitoring and modeling of electricity consumption through developing models or load profiles for appliance use in buildings, as shown in Figure 1. The figure denotes the electricity consumption analytical process, which is described as follows:

Step 1: Recording of appliances usage in the building

Step 2: After measurements of consumption of appliances has been recorded, getting electricity price and using this information to calculate energy costs

Step 3: Using costs estimates to show the costs of appliance usage and their contribution to total consumption in the building.

To determine the recommended technique for data collection and monitoring of electricity consumption, an extensive review of relevant power meters used for data collection was conducted. The information compiled focuses on some of the characteristics of these meters.

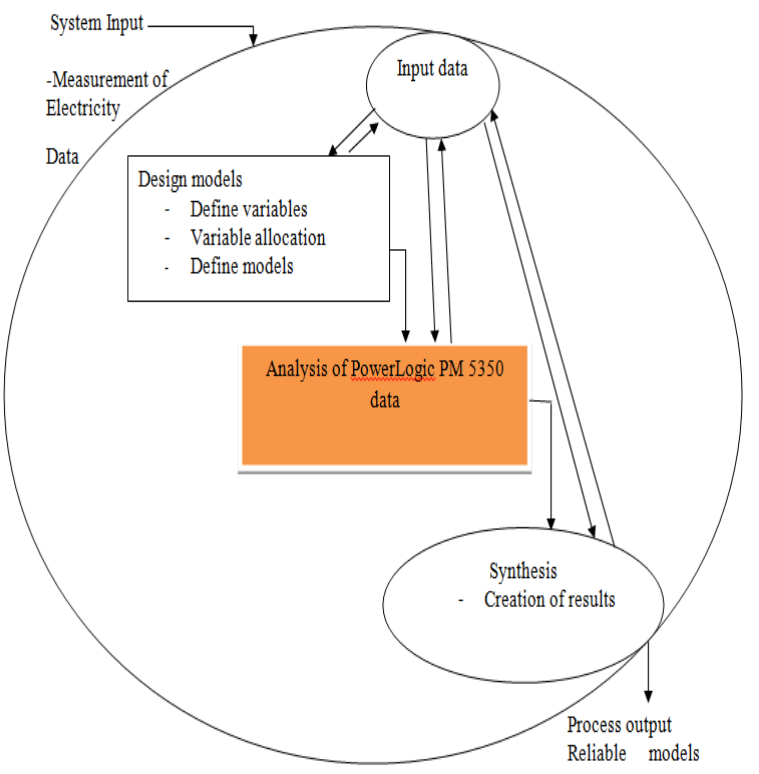

Figure 1 Computation of estimates for electricity consumption
Meanwhile, the electricity consumption used in the analysis and computations for this research work consisted of historical power consumption taken from aggregate daily recordings using the PowerLogic PM 5350 (see Figure 2).

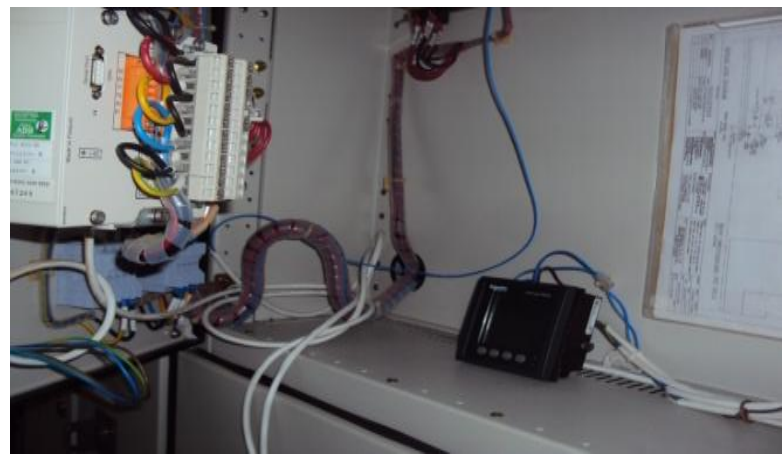

Figure 2 The PowerLogic PM 5350

The data samples for this study (2009-2012) were drawn from the west campus of UNIMAS. The university is made up of the old east campus and the new west campus. Data recordings from power bills provided by ASSETS were used for 2009-2012. For the purpose of applying power-saving measures to appliance usage in the building, the power meter, PowerLogic PM5350 was installed in FCSIT. Data was recorded for individual electric appliances at FCSIT between January and December of 2013 using this power meter. The study was conducted in level 1 ( $1^{\text {st }}$ floor $)$ of the FCSIT building. In applying power-saving measures to lighting, LED bulbs were used for the study, while air conditioning system was switched off between $6 \mathrm{pm}$ and $6 \mathrm{am}$.

Models are used in the power industry for accurate electricity consumption modeling since they are useful for resource allocation. It should be noted that daily consumption patterns can sometimes vary, depending on factors such as occasional breakdowns in the air-conditioner units and also on occupancy pattern on campus such as inter-semester or inter-session holidays, resulting in reduced electricity consumption. For the modeling process, average daily data sets for the years 2009 to 2012 were considered for developing the building's load profiles. In order to develop load profiles for individual appliances, data collection was done using the installed power meter for measuring appliance daily usage between January and December 2013. To illustrate the behavior of the proposed technique and accuracy of the models, measurements were taken for 2013 and compared with measurements from the power grid for that same period. In this manner, simultaneous estimates are obtained for the different models developed in this research work. Variables needed to develop consumption model for each appliance include the previous meter readings of daily consumption for each appliance, and their time of use. The energy grid was installed in the building to take consumption readings for Sarawak Electricity Supply Corporation (SESCO) as displayed in Figure 3. 


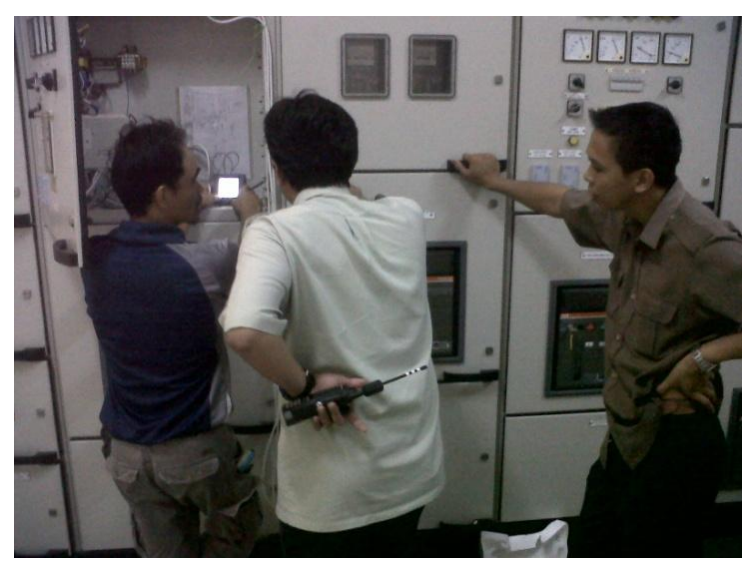

Figure 3 Energy grid for taking consumption measurements for SESCO

This research utilized individual appliances which are different in their control and usage pattern for data collection. This included appliances which are switched on and off manually such as air-conditioners; appliances which are automatically switched off such as the desktop (PCs) computers in the building, where timing settings have been applied to them. The use of energy-saving LED bulbs was also considered in this study. The closed circuit television (CCTV) used back up batteries as a control technique. gutter.

\section{LOAD PROFILE FOR A BUILDING}

In applying the adapted time-series regression (ATSR) technique to develop the load profile for FCSIT building, the electricity consumption for the whole FCSIT building for 2009-2012 is analysed to describe the consumption pattern for the different years. This is done by modelling monthly consumption for the building for 4 years. The data set contains the whole building consumption from the energy grid as provided by Asset Management Division. The data is graphed as shown in Figure 4.

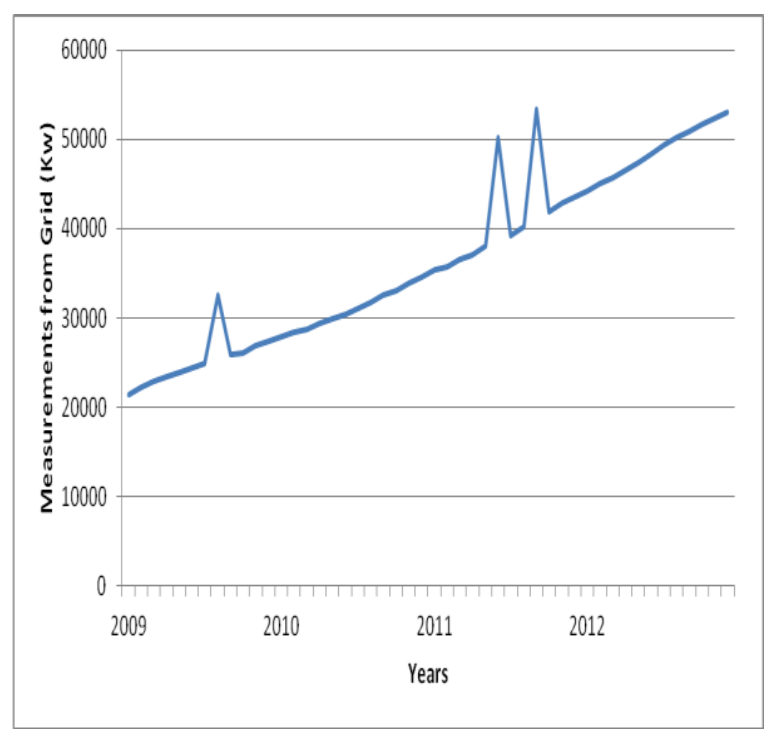

Figure 4 Daily electricity consumption for FCSIT building (from January 2009 to December 2012)

Based on Equation 1, the results from analyzing the consumption model for 2009-2012 gives; $\alpha=31804.93$, $\beta=22.23, R^{2}$ (coefficient of determination) is given as 0.96 , which indicates that $96 \%$ of the variation in electricity consumption is explained by changes in time, $t$.

The data obtained from Asset Management Division, as displayed by Figure 4, shows that the highest amount of electricity consumed in 2009 was in December with $75.58 \mathrm{Kw}$ consumed. This is relatively low compared with the highest amount consumed in 2010, which was $137.72 \mathrm{Kw}$ in December; $136.58 \mathrm{Kw}$ was consumed in December 2011; and 146.61 Kw was consumed in November 2012. Overall, there was an increasing trend in actual consumption from 2009 to 2012, except for the months of May to August, where there was a decline. This decrease was due to students being on inter-session vacation during these months; hence there was a decrease in the amount of electricity consumed. The peak month for all the years was in December. This was due to high occupancy level at that time of the year and energy resources were stretched.

The graph also show some weird drops in consumption level because measurements were taken on weekends, where consumption is particularly lower than the rest of the week, especially on Sundays. In some cases there is an upward trend in electricity consumption in the faculty building, which can be attributed to high occupancy in the building such as when the university was in full academic session. Occasionally, electricity consumption dropped drastically as a result of the air conditioning system not functioning. For instance, in October 2009, power consumption dropped to $20193 \mathrm{KwH}$ due to air conditioning system malfunction. Thus, the air conditioning system is seen as a major contributor to load electricity consumption.

The electricity consumption for the FCSIT building over the years 2009-2012 is given in Table 1.

Table 1 Total consumption for 2009-2012

\begin{tabular}{|c|c|c|}
\hline Year & $\begin{array}{c}\text { Total } \\
\text { consumption } \\
\text { (Watts) }\end{array}$ & $\begin{array}{c}\text { Total } \\
\text { consumption } \\
\text { (Kilowatts) }\end{array}$ \\
\hline 2009 & $8,969,969$ & 8,969 \\
\hline 2010 & $11,307,331$ & 11,307 \\
\hline 2011 & $14,298,057$ & 14,298 \\
\hline 2012 & $17,797,986$ & 17,797 \\
\hline
\end{tabular}

Table 1 show there was a wide gap in electricity consumption in the building between 2009 and other years because population of students and staff has increased progressively over the years, so also has demand for electricity for appliances usage. The percentage increase for 2009-2010 is $26.7 \%$, between 2010 and 2011 is $26.45 \%$, and the percentage increase between 2011 and 2012 is $24.47 \%$. The table captures electricity consumption readings from 2009-2012, and shows that the electricity consumed has been following an increasing trend over the years. Indeed, Table 1 above show power consumption significantly increasing from January to December each year. Increasing consumption from 2009 to 2012 can be attributed to growth in students' and staff population, buildings and faculties. The jumps in the graphs signify either a drastic reduction in consumption, when students are not in session or a sudden increase in 
consumption probably due to exam time when the biggest hall in UNIMAS, DeTAR, is being used for examinations.

Demand for electricity has had an upward trend, as indicated when electricity consumption steadily increased from 2009 to 2012. This makes it imperative for more efficient use of electricity and for the development of models that will assist in its efficient use.

\section{LOAD PROFILES FOR INDIVIDUAL APPLIANCE USE}

The ATSR model is utilized to characterize electricity consumption patterns of a range of domestic appliances. As mentioned earlier, datasets of daily electricity load (measured in watts) were collected from FCSIT, UNIMAS between January and December 2013. Data collection was conducted by taking measurements from electric appliances connected to installed power meters. Data quality for the measurements was generally high because appliances were connected directly to the meters and actual readings were taken from them. It is intended that a database of individual appliance electricity consumption and usage patterns will support a large-scale simulation to explore different techniques for electric load modeling, and improving energy usage efficiency. The load profiles for individual appliances vary. Some appliances are 'always switched on'. Other appliances are not constantly switched on and depend on occupancy, occupant behavior and weather conditions, which vary between buildings. The load profiles of energy usage of the air-conditioner, lighting, computers and the CCTV were developed in order to investigate the impact of electric appliance use on the electricity network. In developing the load profile in buildings by showing the consumption for each

appliance, it is possible to analyze the contribution of individual appliances to the electricity network (Figure 5).

Figure 5 shows measurements obtained from the installed power meter for different electric appliances. The application of power-saving measures on the appliances was conducted at different time periods.

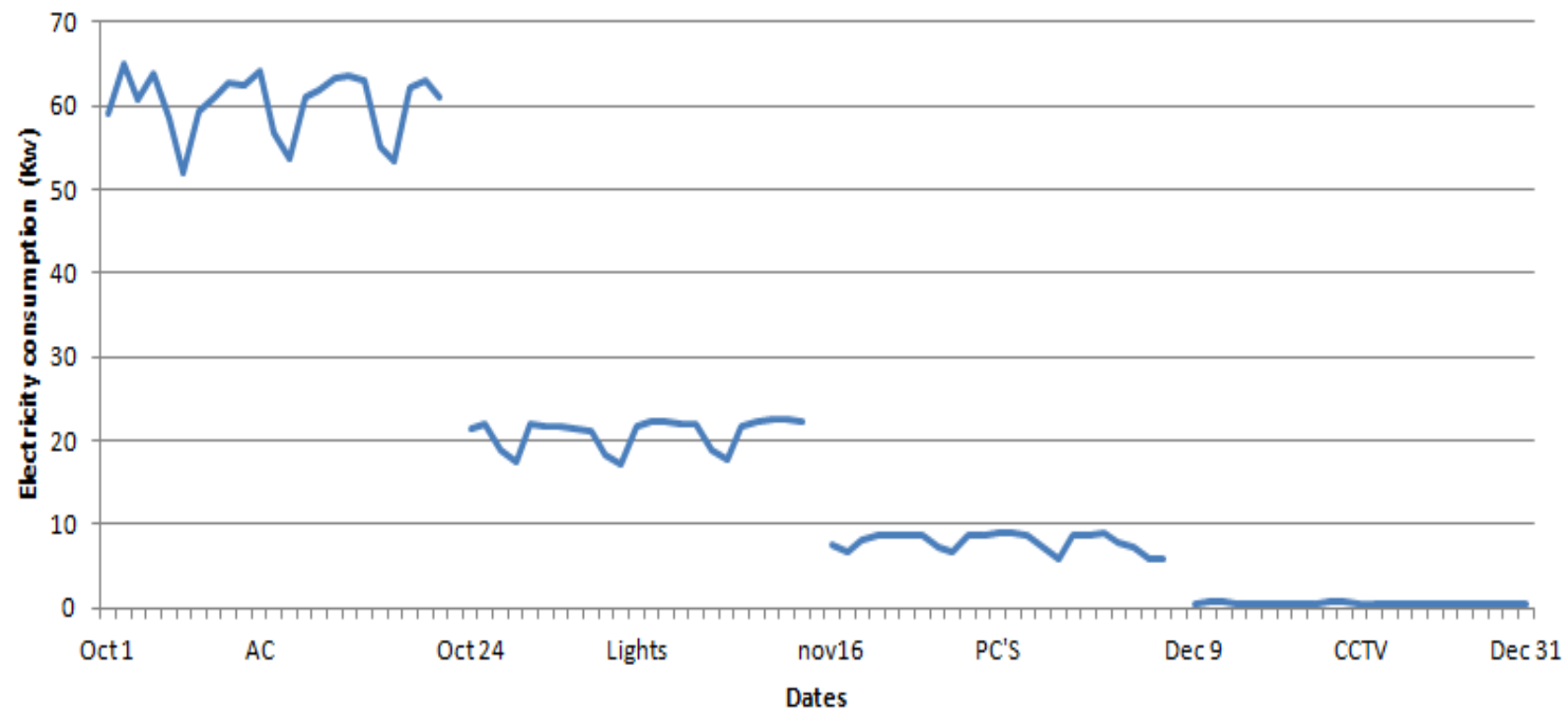

Figure 5 Daily electricity consumption measurements for appliances

Figure 5 shows measurements obtained from the installed power meter for different electric appliances. The application of power-saving measures on the appliances was conducted at different time periods.
The descriptive statistics of measured data for the different time periods are given in Table 2 . 
Table 2 Descriptive statistics of measured data

\begin{tabular}{|c|c|c|c|c|}
\hline \multirow[t]{2}{*}{ Statistics } & \multicolumn{4}{|c|}{ Appliance (KwH) } \\
\hline & $\begin{array}{c}\mathrm{AC} \\
\text { (Oct 1-Oct 23) }\end{array}$ & $\begin{array}{c}\text { Lighting } \\
\text { (Oct 24-Nov 15) }\end{array}$ & $\begin{array}{c}\text { Computers } \\
\text { (Nov 16-Dec 8) }\end{array}$ & $\begin{array}{c}\text { CCTV } \\
\text { (Dec 9-Dec 31) }\end{array}$ \\
\hline Minimum & 50 & 17 & 5 & 0.45 \\
\hline Maximum & 66 & 23 & 9 & 0.7 \\
\hline Mean & 40.39 & 14.05 & 5.95 & 0.58 \\
\hline $\begin{array}{l}\text { Standard } \\
\text { deviation }\end{array}$ & 2.51 & 1.21 & 1.06 & 0.07 \\
\hline
\end{tabular}

The average daily consumption for air-conditioners is 40.39 $\mathrm{KwH}$; lighting is $14.05 \mathrm{KwH}$; computer is $5.95 \mathrm{KwH}$; while that of the CCTV is $0.58 \mathrm{KwH}$. The standard deviation of the CCTV is the smallest $(0.07 \mathrm{KwH})$, while that of airconditioners is the biggest $(2.51 \mathrm{KwH})$. This shows that the differences in consumption for air-conditioners are more spread out than those for CCTV. For example, Figure 5 shows some deeps and upward trend in consumption for airconditioners, while there is a consistent uniformity in consumption for the CCTV. The drops in consumption values over the measurement period is because consumption of electric appliances is low during weekends since less activity takes place in the campus during weekends. Meanwhile, more activities take place on Saturdays than Sundays. As expected, the rate of consumption is high for air-conditioners and lighting, while it is low for computers and CCTV. The load profiles developed for individual appliance gives information about habits of household inhabitants and the average frequency these appliances are used. The summary of the power used by individual appliances, considered in this study, in the building are given in Table 3 . The results obtained consist of peak daily power consumption, total daily energy consumption, and average daily power consumption.

Table 3 Summary of power used by individual appliances

\begin{tabular}{|l|c|c|c|c|}
\hline \multirow{2}{*}{$\begin{array}{l}\text { Power } \\
\text { consumption } \\
\text { (kilowatts) }\end{array}$} & $\begin{array}{l}\text { Air-conditioner } \\
\text { (Oct 1-Oct 23) }\end{array}$ & $\begin{array}{l}\text { Lighting } \\
\text { (Oct 24-Nov 15) }\end{array}$ & $\begin{array}{l}\text { Computers(Nov } \\
\text { 16-Dec 8) }\end{array}$ & $\begin{array}{l}\text { CCTV } \\
\text { (Dec 9-Dec 31) }\end{array}$ \\
\cline { 2 - 5 } \\
\hline $\begin{array}{l}\text { Peak daily power } \\
\text { consumption }\end{array}$ & 65.07 & 22.69 & 8.98 & 0.68 \\
\hline $\begin{array}{l}\text { Average daily } \\
\text { power } \\
\text { consumption }\end{array}$ & 40.39 & 14.05 & 5.95 & 0.58 \\
\hline $\begin{array}{l}\text { Total power } \\
\text { consumption }\end{array}$ & $1,386.31$ & 482.14 & 181.90 & 13.32 \\
\hline
\end{tabular}

After taking into consideration all the different time periods of data collection for appliances in the building, Table 3 shows that air-conditioners had high power consumption. Its peak daily power consumption between Oct 1 and Oct 23, 2013 was 65.07 kilowatts, total power consumption was $1,386.31$ kilowatts and its average daily power consumption was 40.39 kilowatts. The peak daily power consumption for lighting between Oct 24 and Nov 15, 2013 was 22.69 kilowatts, total power consumption was 482.14 kilowatts and its average daily power consumption was 14.05 kilowatts. The figure shows the air-conditioner and lighting had high peak daily power consumption (65.07 kilowatts and 22.69 kilowatts respectively), while computers and closed circuit television had low power consumption (8.98 kilowatts and 0.68 kilowatts respectively). Therefore air-conditioner and lighting can be classified as high-power consumption appliances while computers and CCTV are classified as low-power consumption appliances.

Factors affecting usage pattern or performance during appliance use differ from one situation to another and from one appliance to another. That is, some variation in environmental conditions might significantly affect the usage pattern for a specific appliance. The number of occupants in a building may also affect the usage pattern, appliance loads and performance of most appliances. 


\section{CONCLUSION}

This paper describes the ATSR model for modeling usage characteristics of appliances in order to explain their typical consumption patterns. This study has described and explained the behavior of the appliances for each appliance type and also meter readings for a building. Electricity consumption costs and the efficient use of electric appliances are becoming important components in power management systems, especially to consumers. The ATSR model simulates load profiles for a building and individual appliances from electricity consumption. The ATSR model showed improvements over previous models by describing variations in consumption and trend of individual appliance consumption. The variations and trends in the consumption pattern of appliances were analyzed using the standard error (SE) and coefficient of variation descriptive statistics.

This study develops the load usage and energy consumption pattern of the building and individual appliances. The data obtained for the study were stored in a database with information about appliance usage. Measurements obtained for each appliance were used to simulate its behavior over periods of time in order to explore the benefits of developing load profiles for buildings and individual appliances. Obtaining the data of appliances individually will help to identify the energy consumption of each appliance, helping consumers to use their appliances in a more efficient manner.

\section{REFERENCES}

[1] Athukorala PP. W, Wilson C (2010) Estimating short and long-term residential demand for electricity: New evidence from Sri Lanka. Energy Econ 32:S34-S40. doi: 10.1016/j.eneco.2009.08.005

[2] Ortiz J, Guarino F, Salom J, et al. (2014) Stochastic model for electrical loads in Mediterranean residential buildings: Validation and applications. Energy Build 80:23-36. doi: 10.1016/j.enbuild.2014.04.053

[3] Widén J, Lundh M, Vassileva I, et al. (2009) Constructing load profiles for household electricity and hot water from time-use data-Modelling approach and validation. Energy Build 41:753-768. doi: 10.1016/j.enbuild.2009.02.013

[4] Grandjean A, Binet G, Bieret J, et al. (2011) A functional analysis of electrical load curve modelling for some households specific electricity end-uses. 1-24.

[5] Bacher P, Madsen H, Nielsen HA, Perers B (2013) Short-term heat load forecasting for single family houses. Ind Electron Soc 5741 - 5746.

[6] Weisstein E (2012) Newton's Method.

[7] P. Ozoh, S. Abd-Rahman, J. Labadin MA (2014) Visualizing a Control Strategy for Estimating Electricity Consumption. Proc AVI 2014 Work Foster Smart Energy Appl through Adv Virtual Interfaces 43-47. 